\title{
Recent outbreaks of severe hepatitis A virus infections in Vienna
}

\author{
David Bauer ${ }^{1,2}$ (D) Anna Farthofer ${ }^{1}$ - David Chromy ${ }^{1,2,3} \cdot$ Benedikt Simbrunner $^{1,2} \cdot$ Lisa Steininger $^{1,2}$. \\ Caroline Schmidbauer ${ }^{1,2,4} \cdot$ Teresa Binter $^{1,2} \cdot$ Michael Trauner $^{1} \cdot$ Mattias Mandorfer $^{1,2} \cdot$ Ralf Schmidt $^{5}$. \\ Florian Mayer ${ }^{5} \cdot$ Heidemarie Holzmann $^{6} \cdot$ Robert Strassl $^{5} \cdot$ Thomas Reiberger $^{1,2,7}$ (C)
}

Received: 23 June 2020 / Accepted: 26 August 2020 / Published online: 17 September 2020

(C) The Author(s) 2020

\begin{abstract}
To explore the epidemiology and clinical course of hepatitis A virus (HAV) infections at the Vienna General Hospital. We retrospectively identified patients who were tested positive for HAV-IgM at the Vienna General Hospital form Q1/2008 to Q3/ 2018. Our definition of severe HAV infection was AST and/or ALT $>5 \times$ above the upper limit of normal (ULN); and liver dysfunction as (i) hepatic encephalopathy or ammonia $>100 \mu \mathrm{mol} / \mathrm{L}$, (ii) coagulopathy with INR $>1.5$, or (iii) jaundice with bilirubin $>5 \mathrm{mg} / \mathrm{dL}$. A total of $578 \mathrm{HAV}-\operatorname{IgM}(+)$ were identified, including $31(5.4 \%)$ and $38(6.6 \%)$ without and with liver dysfunction, respectively. A proportional increase in severe HAV cases with and without liver dysfunction occurred in 2016/ 2017 with $(21.5 \%$ (vs. $8.0 \%$ in the years before; $p<0.001)$. Thirty-seven $(53.6 \%)$ patients with severe HAV were hospitalized, 6 (9\%) required ICU support, and one patient received liver transplantation within 30 days. Patients with severe HAV and liver dysfunction were more often male $(60.5$ vs. $43.1 \%, p=0.055)$ and younger $(31.5$ vs. 63 years, $p<0.001)$ as compared with other HAV-IgM (+) cases. The observed increase of severe HAV infections in Vienna in 2017 among young males, coincided with a multinational HAV outbreak among MSM. Our data suggests a higher likelihood of severe courses of hepatitis A in MSM. Vaccination against HAV should be recommended for risk groups.
\end{abstract}

Keywords Hepatitis A $\cdot$ Viral hepatitis A · Hepatitis A epidemiology · Austria

\section{Introduction}

Hepatitis A virus (HAV) infection is usually a self-limiting viral disease with a reported case fatality of $0.1-0.3 \%[1,2]$. According to estimations by the WHO, HAV caused 16,900 and 11,200 deaths worldwide in 2005 and 2015, respectively [3]. Persons aged 40 years and older are more susceptible to HAV-associated complications and mortality than younger persons [4]. Transmission usually occurs via the fecal-oral route as per contaminated food or water or person-to-person contact or smear transmission. While effective antiviral therapies are available for other types of viral infections, treatment options for acute HAV infection are limited to symptomatic measures $[5,6]$. The HAV belongs to the family of Picornaviridae of the genus Hepatovirus and is a nonenveloped single-stranded RNA virus [7]. While only one

Electronic supplementary material The online version of this article (https://doi.org/10.1007/s10096-020-04028-x) contains supplementary material, which is available to authorized users.

Thomas Reiberger

thomas.reiberger@medunwien.ac.at

1 Division of Gastroenterology and Hepatology, Department of Medicine III, Medical University of Vienna, Vienna, Austria

2 Vienna HIV \& Liver Study Group, Medical University of Vienna, Vienna, Austria

3 Department of Dermatology, Medical University of Vienna, Vienna, Austria
4 Division of Gastroenterology and Hepatology, Department of Medicine II, Wilhelminenspital, Vienna, Austria

5 Institute of Clinical Virology, Department of Laboratory Medicine, Medical University of Vienna, Vienna, Austria

6 Department of Virology, Medical University of Vienna, Vienna, Austria

7 Division of Gastroenterology \& Hepatology, Department of Internal Medicine III, Medical University of Vienna, Waehringer Guertel 18-20, A-1090 Vienna, Austria 
serotype exists, six HAV genotypes have been described. Genotype (GT)-1A and, to a lesser degree, GT-1B are prevalent in central Europe; GT-3A is usually associated with recent travel to endemic regions, while GT-2A is very rare $[8,9]$.

In most immunocompetent adults, acute HAV infection is asymptomatic and self-limiting. At the same time, higher rates of symptoms have been associated with older age, prior liver disease, coinfection (e.g. HCV), as well as with coinfection with the human immunodeficiency virus (HIV) - which may lead to higher bilirubin levels and HAV relapse rates [10, 11]. In patients developing fulminant liver failure in the course of an acute HAV infection, liver transplantation might be required in as many as $>50 \%$ of infections [12].

Vaccinations against HAV have been available since the 1990s in Europe and the USA [13]. These vaccinations are part of the recommended vaccination scheme, in Austria and internationally for children and groups at risk (including health care workers and people who inject drugs and travelers to endemic countries) $[14,15]$.

Austria is a low HAV endemicity country with an incidence of 0.91 reported infections/100,000 inhabitants/year [16]. Other low-endemic countries in the European Union (EU) and European Economic Area (EEC) report an incidence of $\sim 2$ infections $/ 100,000$ inhabitants/year [17]. The reported seroprevalence of HAV-IgG(+) in low-seroprevalence EU and ECC countries, including Austria, was $12.3 \%$ in 2000; conversely, the susceptibly rate was $87.7 \%$. It reportedly increased in the past decades in these countries [18]. Concomitantly, a shift to infection from early childhood to adulthood was observed, leading to an increase in infections later in life and concordantly to an increase in acute symptomatic hepatitis A [17].

Several recent outbreaks of HAV infections have been reported in 2013, 2016/17, and 2018. Two of these outbreaks in 2013 and one in 2018 in Sweden and Austria from June to September were linked to the consumption of frozen strawberries [19]. While a multinational outbreak in 2016 and 2017 was disproportionally affecting MSM [20].

Patients exhibiting a severe course of the disease should be identified early, to provide sufficient supportive care and monitoring for the occurrence of acute liver failure. To improve on existing epidemiological data and to add clinical context, we aimed to report the number and course of acute HAV infections at a large tertiary care center and provide further insights on the individuals who develop severe hepatitis A (HA) hepatitis.

\section{Patients and methods}

\section{Study cohort}

The goal of this study is to describe the epidemiology, as well as the clinical course of infections with HAV at the Vienna
General Hospital, Austria, from Q1/2008 to Q3/2018. A query obtained the test results of all patients tested for HAV-IgM and HAV-IgG in the respective period to the laboratory records of the department of Clinical Virology of the Medical University of Vienna.

\section{Case definitions}

Severe hepatitis was defined as aspartate aminotransferase (AST) $\mid$ (or) alanine transaminase $($ ALT $)>5 \times$ the sex-specific upper limit of normal (ULN; men: $<50 \mathrm{U} / \mathrm{L}$, women: $<35 \mathrm{U} /$ $\mathrm{L}$ for females equally for both AST and ALT). Conversely, we defined HAV-IgM (+) patients without a $5 \times$ increase of transaminases as possible HAV infection and referred to them as $\operatorname{IgM}(+)$. Severe HA hepatitis with liver dysfunction was defined as fivefold increase over the ULN of normal of AST or ALT and at least one of the following criteria: (i) jaundice or serum bilirubin $>5 \mathrm{mg} / \mathrm{dL}$, (ii) hepatic encephalopathy and or plasma ammonia $(\mathrm{NH} 3)>100 \mu \mathrm{mol} / \mathrm{L}$, or (iii) failure of coagulation/international normalized ratio $($ INR) $>1.5$. Cases were partially verified by PCR, where it was available.

HAV-IgM (+) patients with AST or ALT 3-5 $\times$ ULN were considered to likely have HAV infection, although it must be noted that HAV infections without relevant transaminase elevation are observed clinically. To better describe the relationship of the likelihood of infection with increasing transaminases, we also assessed the quantitative results of the HAVIgM testing, where higher titers indicate a higher likelihood of acute infection.

Acute infection with hepatitis B and/or C was ruled out by serological testing and/or PCR in all patients with severe HAV hepatitis, while acute infection with hepatitis E virus (HEV) was ruled out by serologic determination of anti-HEV IgM or HEV PCR, where available. HIV status of patients with severe HAV hepatitis was assessed by HIV-1/2 antigen and antibody testing, as well as PCR for HIV-1 RNA in some cases. If HIV testing was not initially performed, we performed retrospective HIV testing whenever stored samples were available.

Cholestatic disease courses were defined as peak bilirubin $>5 \mathrm{mg} / \mathrm{dL}$ and ALP $\times 2$, the gender-specific ULN.

\section{Clinical parameters and follow-up}

For all HAV-IgM (+), the date of positive testing was defined as the baseline (BL). The following laboratory results from that BL date were recorded: hemoglobin $(\mathrm{Hb})$, platelets (PLT), white blood cell count (WBC), sodium (Na), serum creatinine, AST, ALT, gamma-glutamyl transferase (gGT), alkaline phosphatase (ALP), serum albumin, prothrombin time, INR, bilirubin, and ammonia (NH3). All parameters were used as given by the hospital's laboratory, which is ISO 15189 certified. 
In patients with transaminases (AST and ALT) $>5 \times$ ULN at the day of IgM positivity, the peak ALT value within 30 days before or after IgM positivity was documented, as well as AST, ALT, bilirubin, and INR values in the 30 days following the ALT peak. Clinical information including symptoms, suspected transmission route, travel history, and hospital or ICU admission were obtained from the patient records.

The symptom frequency, as well as the presence of ascites and hepatic encephalopathy, was read out from clinical documentation as well as radiological reports. Death dates were queried from the hospital records as well as from the national Austrian statistical agency Statistik Austria.

\section{Virologic testing for HAV}

The assays used for serological $\operatorname{IgM}$ and $\operatorname{IgG}$ antibody testing were Abbott ARCHITECT $®$ HAV-Ab-IgM for IgM testing. HAV-RNA detection and HAV strain genotyping were performed as recommended by HAVNET [8]. For patients where these results were not available, frozen sera from the date of IgM positivity were obtained, and HAV-RNA PCR testing was performed retrospectively. The quantitative value of the Anti-HAV-IgM-Ab assay was also obtained.

\section{Statistical analysis}

Parameters were described giving the mean \pm standard deviation (SD) for parametric variables, while the median and the interquartile range (IQR) were used for non-parametric variables. The normality of distribution was assessed using Shapiro and Wilk's $W$ test for normality. Group comparisons were performed using the two-sided Welch two-sample $t$ test and the non-paired Wilcoxon-Mann-Whitney-Test, as appropriate. Comparisons of frequencies of categorical variables were performed using the Pearson's chi-squared test or the Fisher's exact test, as appropriate. Severe HAV-IgM (+) infections without liver dysfunction were compared with HAV$\operatorname{IgM}(+)$ infections with liver dysfunction. The male to female ratio was ascertained by dividing the number of males by the number of females in the given periods.

We performed the statistical analysis using the $\mathrm{R}$ language for statistical computing [21], using the following packages: dplyr [22], openx [23], tableone [24].

\section{Results}

Of 178,940 persons included in this study, 178,095 (99.5\%) were tested for anti-HAV-IgG, and 112,200 (63.0\%) were anti-HAV-IgG positive. A total of 737 of $176,931(0.4 \%)$ persons tested for anti-HAV-IgM were tested positive (see Fig. 1 and Table 1).
Laboratory records were available for 578/737 (78.4\%) patients. Among the 578 anti-HAV-IgM (+) individuals, 509 $(88.1 \%)$ individuals were HAV-IgM (+) without severe HA, while 69 (11.9\%) showed a severe HA hepatitis course: 31 (5.4\%) of the severe HAV infections did not develop liver dysfunction, while 38 (6.6\%) did develop severe HA hepatitis with liver dysfunction. The rate of HAV-RNA PCR positivity and the median quantitative HAV-IgM titer was lowest in patients with low transaminases and increased concurrently (s. supplemental Table S1). In the 21/38 (55.2\%) HAV-IgM (+) infections with severe disease and liver dysfunction, HAV-RNA PCR results were available, and HAV-RNA viremia was confirmed in all these tests. HAV genotype was available in 21 patients with severe HAV: 16 had HAV-GT1A, 4 had GT-1B, and one patient had GT-3A.

The number of anti-HAV-IgM-tested patients decreased between the years 2014 and 2015, while the percentage of IgM (+) increased in the years 2016 and 2017 (Fig. 2a, supplemental figure 1). The absolute number of HAV-IgM (+) decreased towards the end of the last decade. In contrast, the fraction of the HAV infections taking a severe course was particularly high in the years 2016 and 2017. The male to female ratio was 2.17 in 2017, which was higher than in 2008-1015, where it ranged from 0.465-1.190 (Fig. 2b and supplemental Table S3).

\section{Risk factors for HAV transmission}

For $25.8 \%(8 / 31)$ and $31.6 \%$ (12/38) of all patients with severe hepatitis, travel history was documented: countries that these patients had traveled to included India 3/69 (4.4\%), Sudan 2/69 (2.9\%), Serbia 2/69 (2.9\%), Egypt 1/69 (1.5\%), Namibia 1/69 (1.5\%), and Syria 1/69 (1.5\%). A total of 4/38 $(10.5 \%)$ of patients with severe HA hepatitis and liver dysfunction were documented to be MSM, while no patients without liver dysfunction were reported to be MSM.

\section{HIV coinfection}

Among patients with severe HA, HIV coinfection was assessed by the treating physician or retrospectively in 28 of 69 (40.6\%) patients. Importantly, none of $8(0 \%)$ severe HA without liver dysfunction, but 4 of 20 (20\%) HA with liver dysfunction, respectively, were tested HIV (+) (see also supplemental Table S4).

\section{Demographic, clinical, and laboratory characteristics of HAV infections (Tables 1, 2)}

The median age of patients with severe HA hepatitis (regardless of liver dysfunction) was markedly lower than that of HAV-IgM (+) non-severe patients (36/31.5 vs. 63 years, $p<0.001)$. More male patients had severe HA hepatitis with liver dysfunction $(60.5 \%)$ than without $(38.7 \%)$. At the time of diagnosis, platelets were markedly lower, while AST and 
Fig. 1 Study flow chart $(\mid-$ or, HAV - hepatitis A virus, HA hepatitis $\mathrm{A},(+)$ - positive, $n$ - number, IgM - immunoglobulin M, w/o - without, TA - transaminases, ULN - upper limit of normal, INR - international normalized ratio, Bili - bilirubin)

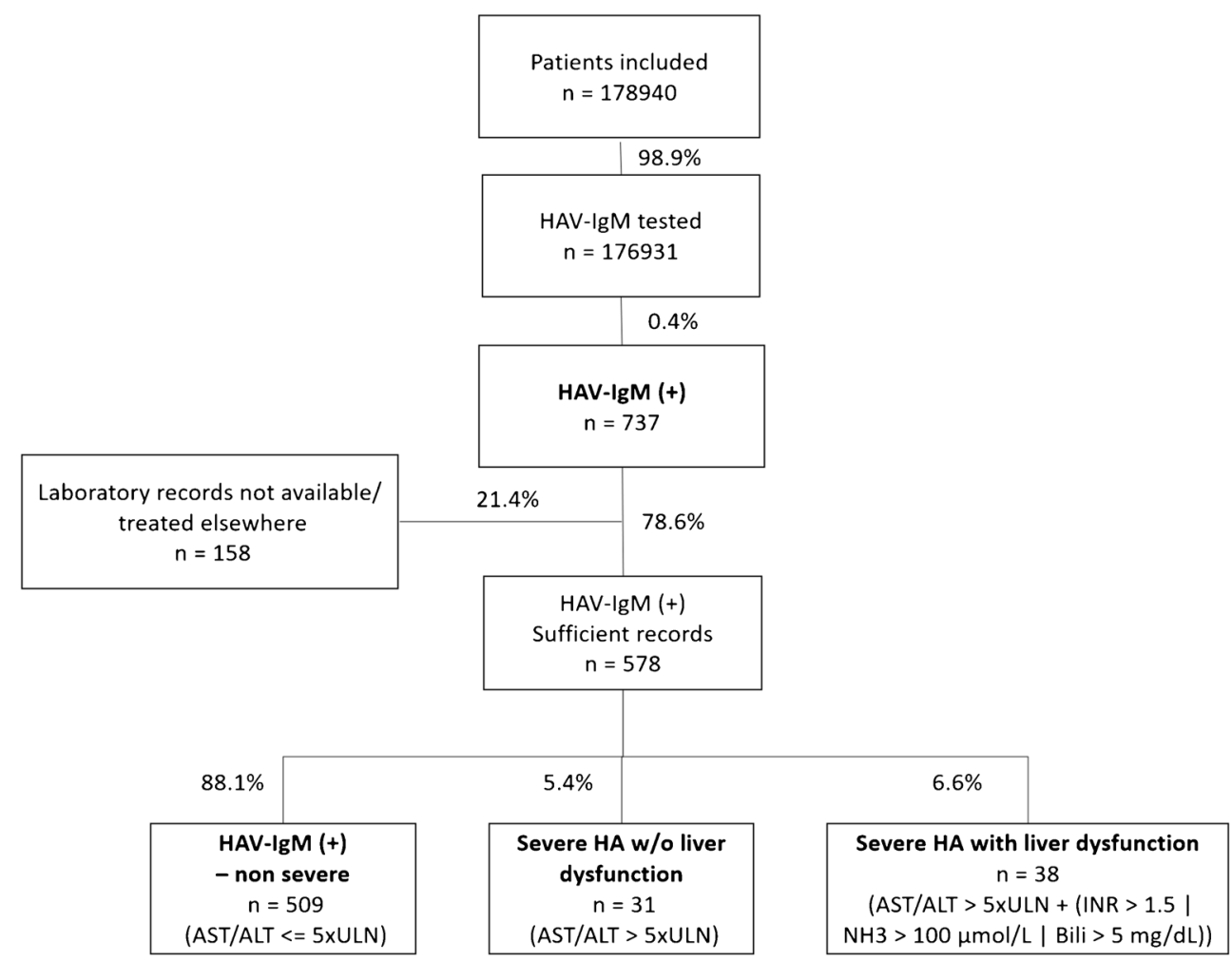

ALT levels (by definition) and serum bilirubin levels were significantly increased in severe HA hepatitis courses. These biochemical alterations were more pronounced in infections with liver dysfunction than in those without liver dysfunction: peak AST (468 vs. $1599 \mathrm{U} / \mathrm{L} ; p<0.001$ ), peak ALT (535 vs. $2857 \mathrm{U} / \mathrm{L} ; \mathrm{p}<0.001)$, peak Bili (2.13 vs. $8.33 \mathrm{mg} / \mathrm{dL} ; \mathrm{p}<$ $0.001)$, peak INR (1.32 vs. $1.5 ; p=0.083)$.

The symptoms recorded most commonly in severe HAV infection without/with liver dysfunction course were as following: jaundice (12.9/60.5\%), fatigue/malaise (19.4/ $81.6 \%)$, dark urine $(19.4 / 39.5 \%)$, fever $(38.7 / 47.4 \%)$, nausea/vomiting (35.5/86.8\%), and abdominalgia (41.9/ $52.6 \%)$. Pruritus was noted in $(3.2 / 22.6 \%)$ of infections. Of these, jaundice, dark urine, fatigue/malaise, nausea/vomiting, and abdominalgia were significantly more common in patients with liver dysfunction.

\section{Cholestasis}

We observed bilirubinemia $>5 \mathrm{mg} / \mathrm{dL}$ in $8 / 509$ (1.6\%) $\mathrm{IgM}$ (+) patients, in 6/31 (19.4\%) patients with severe HA hepatitis without liver dysfunction, and in 38/38 (100\%) patients with liver dysfunction. A total of 19/44 (43.2\%) also had a peak ALP $>2 \times$ gender-specific ULN, which we would consider as a cholestatic course. Bilirubinemia on day 30 after ALT peak was recorded in two patients, which were lost to follow-up, or their bilirubin levels fell below $2 \mathrm{mg} / \mathrm{dL}$ within 90 days of ALT peak. Among all patients with severe HA hepatitis and bilirubinemia $>5 \mathrm{mg} / \mathrm{dL}$, only $2 / 38(7.1 \%)$ experienced prolonged hyperbilirubinemia for longer than 29 days.

\section{Clinical course and outcomes of severe HA hepatitis (Fig. 3, Table S2)}

There was no statistically significant difference in hospital admission rate between in HA hepatitis patients without and with liver dysfunction (64.5\% vs. $44.7 \%, p=0.096)$.

The observed course of severe HA hepatitis was in concordance with previously published accounts [25]. AST was uniformly highest on the same day as ALT. The highest INR was most often measured on the same day [IQR: 1 day] as the highest ALT. The serum levels of bilirubin peaked after 3 days [IQR: 4 days] (Fig. 3a-d).

In-hospital mortality and 30-day mortality in severe hepatitis without and with liver dysfunction were $2 / 31$ (6.5\%) and $0 / 38(0 \%)$. Both patients died of no-liver related causes.

A summary of the detailed clinical characteristics and outcomes of patients with severe HA hepatitis and liver dysfunction with confirmed HAV-RNA viremia is shown in the supplementary Table S5.

\section{Discussion}

During the study period from Q1/2008 to Q3/2018, we identified 578 patients with documented acute HAV-IgM 


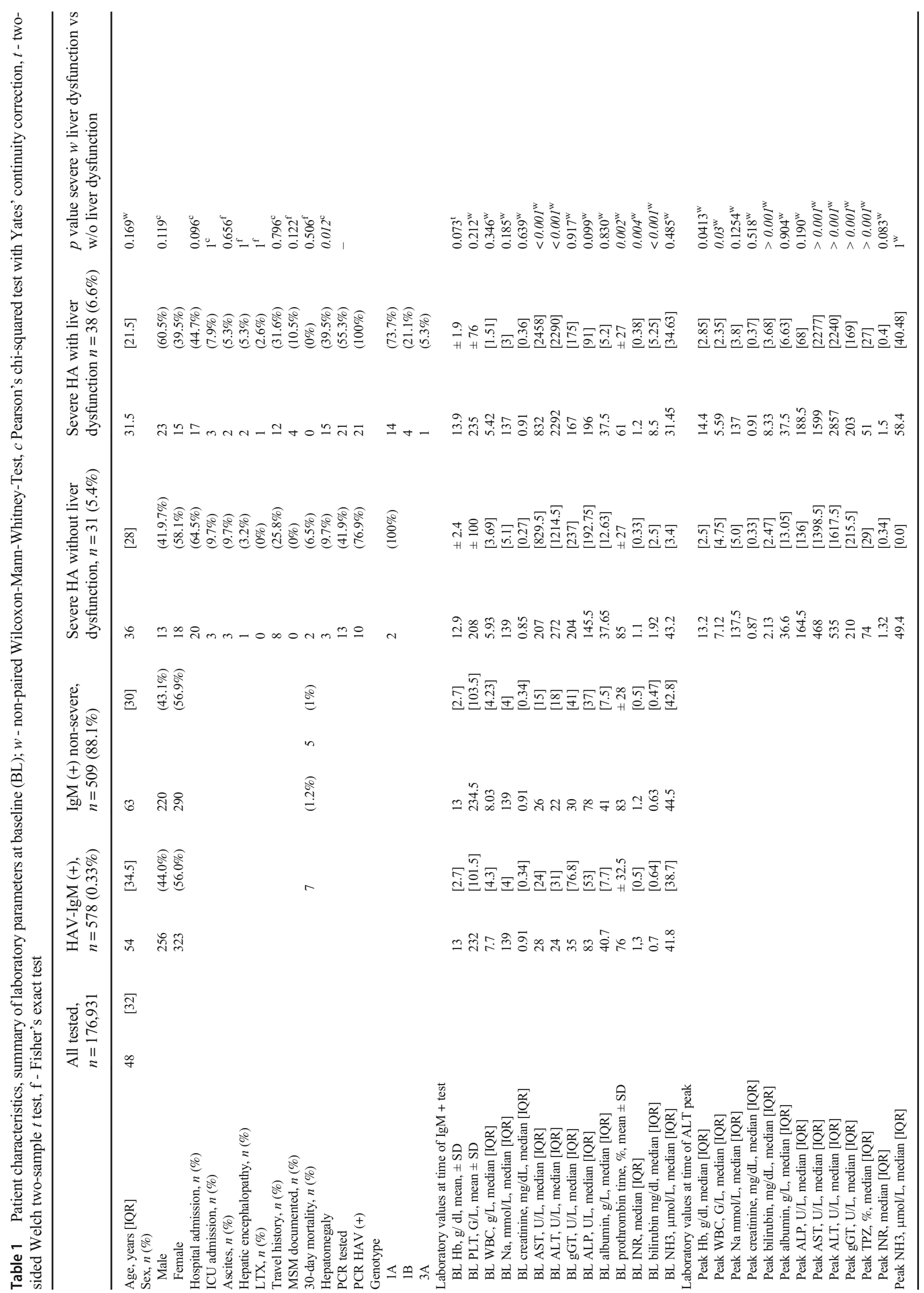


Fig. 2 a Number of HAV-IgM (+) patients tested per year. b Yearly incidence of HAV$\operatorname{IgM} / \mathrm{RNA}(+)$ with disease course shown as IgM (+) non-severe (blue), severe w/o liver dysfunction (black), and severe with liver dysfunction (red), the black line and right axis showing the course of male to female ratio over the years in the observation period. (HAV - hepatitis A virus, HA hepatitis A, w/o without, M.FRatio - male-to-female ratio; + positive)

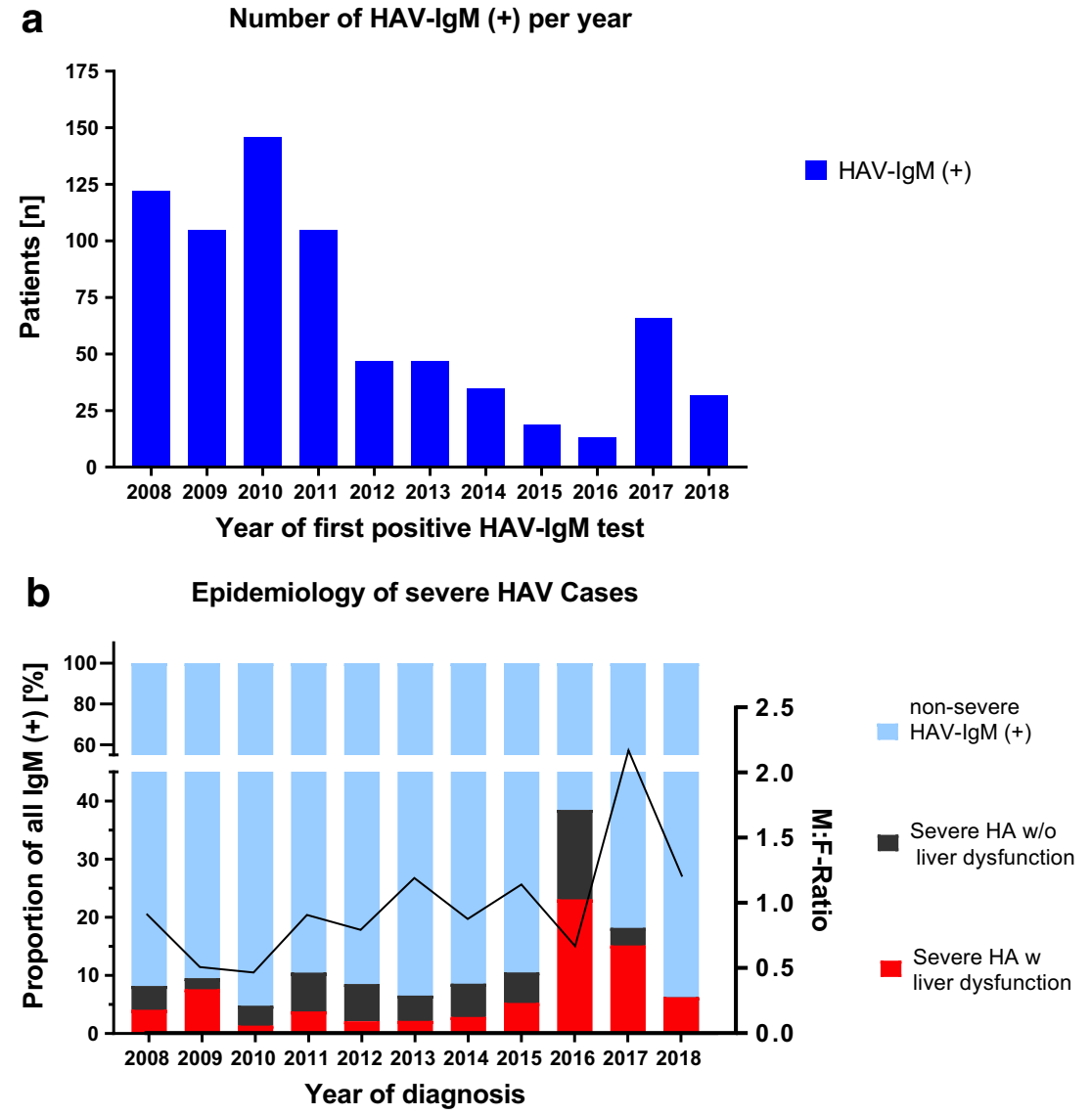

positivity at the Vienna General Hospital. Among these, 509 (88.1\%) showed no signs of severe HA hepatitis. Due to the low endemicity of HAV in Austria, it should be assumed that many of IgM (+) tests in patients without transaminase elevation were unspecific positive tests. Therefore, the group of $\operatorname{IgM}(+)$ non-severe was only used as a baseline for relative numbers. A total of 69 (11.9\%) of patients had severe hepatitis with AST and/or ALT > $5 \times$ ULN. Importantly, 38 (6.6\%) HA patients also developed liver dysfunction. Among the patients tested for HAV genotypes, the HAV-GT-1A and 1B were most prevalent, while only one infection with GT-3A was documented. This GT profile fits well with that endemic to central Europe [8].

After declining rates of HAV infections from 2008 onwards, they rose again in 2016 and 2017. At the same time, the rates of severe HA hepatitis without and with liver dysfunction were higher in 2016 and 2017 than in previous years, and the male-to-female ratio across all IgM positive increased to 2.17 in 2017 while it was in the range of $0.465-1.190$ before. Our findings show an interesting coincidence with reported HAV outbreaks in Europe in 2016 and 2017 that mostly affects MSMs [20]. Some of these outbreaks in the Netherlands were phylogenetically linked with the EuroPridee in Amsterdam in 2016 [26]. Even outbreaks outside of Europe, in Chile and Tel Aviv were also connected with this multinational outbreak in Europe, suggesting a connection of the increase in severe HA in males in 2016 and

Table 2 Symptom frequency in severe HA hepatitis in patients without (w/o) and with (w) liver dysfunction; c - Pearson's chi-squared test with Yates' continuity correction

Symptom frequency

\begin{tabular}{llll}
\hline Symptoms, $n$ & Severe HA & Severe HA & $p$ value severe HA w/o \\
$(\%)$ & without liver & with liver & vs w liver dysfunction \\
& dysfunction, & dysfunction, & \\
& $n=31$ & $n=38$ & \\
& &
\end{tabular}

\begin{tabular}{llllll}
\hline Jaundice & 4 & $(12.9 \%)$ & 23 & $(60.5 \%)$ & $<0.0001^{c}$ \\
Dark urine & 6 & $(19,4 \%)$ & 15 & $(39.5 \%)$ & $0.123^{\mathrm{c}}$ \\
Fatigue/malaise & 6 & $(19.4 \%)$ & 31 & $(81.6 \%)$ & $<0.0001^{c}$ \\
Fever & 12 & $(38.7 \%)$ & 18 & $(47.4 \%)$ & $0.633^{\mathrm{c}}$ \\
Nausea/vomiting & 11 & $(35.5 \%)$ & 33 & $(86.8 \%)$ & $<0.0001^{c}$ \\
Abdominalgia & 13 & $(41.9 \%)$ & 20 & $(52.6 \%)$ & $0.521^{\mathrm{c}}$ \\
Diarrhea & 6 & $(19.4 \%)$ & 8 & $(21.1 \%)$ & $1^{\mathrm{c}}$ \\
Arthralgia & 4 & $(12.9 \%)$ & 1 & $(2,6 \%)$ & $0.166^{\mathrm{c}}$ \\
Loss of appetite & 5 & $(16.1 \%)$ & 13 & $(34.2 \%)$ & $0.154^{\mathrm{c}}$ \\
Hepatomegaly & 3 & $(9.7 \%)$ & 15 & $(39.5 \%)$ & $0.012^{c}$ \\
Pruritus & 1 & $(3.2 \%)$ & 7 & $(18.4 \%)$ & $0.066^{\mathrm{c}}$
\end{tabular}


Fig. 3 a Course of ALT serum levels in severe HA hepatitis with liver dysfunction. b Course of AST serum levels in severe HA hepatitis with liver dysfunction. c Course of bilirubin serum levels in severe HA hepatitis with liver dysfunction. d Course of INR serum levels in severe HA hepatitis with liver dysfunction. (ALT alanine transaminase, AST aspartate transaminase, $\mathrm{d}$ day)
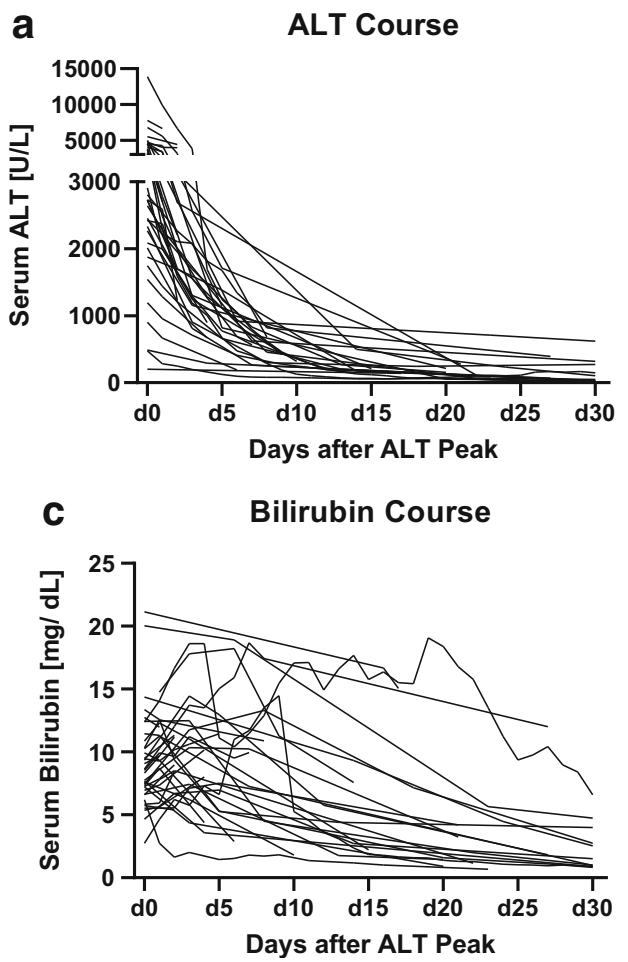

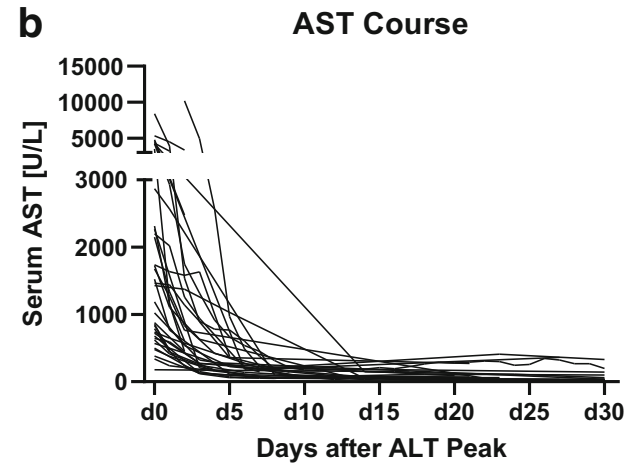

d

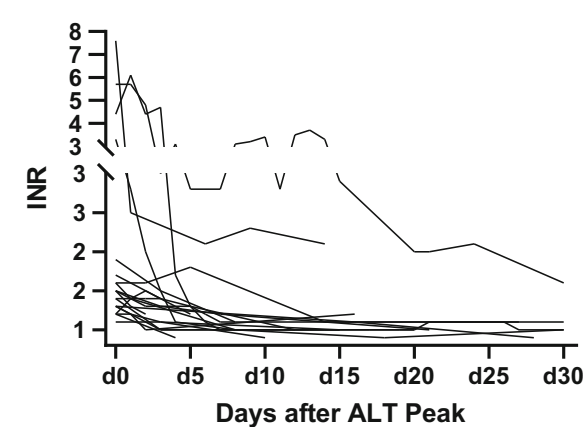

2017 reported for Vienna in this study to the then ongoing HAV outbreak among MSM in and outside Europe [27, 28].

In contrast with some published literature, where older age is a risk factor for complications and severe hepatitis [4, 29], in our cohort, the median age of patients with severe hepatitis was lower than that of patients with HAV-IgM positivity with no signs of a severe course $(36 / 31.5$ vs. 63 years, $p<0.001)$. Our observed age range for severe HA hepatitis was similar to a Mexican study, where patients admitted for severe HA hepatitis had a median age of 30 years [30]. The comparably lower age may be an indicator that MSMs, who are usually not only younger men but also are at a higher risk of contracting HAV infection, might have a higher risk of a severe course of HAV infection.

In those tested for HAV-IgG, 112,200/178,095 (63.0\%) individuals had a past infection or were vaccinated, as indicated by HAV-IgG (+), with concurrent IgM negativity. This indicates a susceptibility rate to HAV of $37.0 \%$ across all age groups, which is lower than the rate in the general population, likely due to higher rates of past infection and vaccination in this cohort of patients at a tertiary hospital.

In severe HA hepatitis with organ dysfunction, recent travel history to endemic regions was documented in $31.6 \%$ of severe HA with liver dysfunction, and $10.5 \%$ of these patients were documented to be MSM. HIV infection is more prevalent among MSM than in the general population and is known to spread through the same multinational networks as eluded to above [31]. HIV coinfection is known to aggravate the clinical disease course of acute HA, leading to increased bilirubinemia and higher symptom burden [11]. HIV status could be determined in about half of our patients with severe HA infection, and importantly $20.0 \%$ were HIV (+) with all of them presenting signs of liver dysfunction. The fact that all cases of severe acute HA with HIV coinfection developed signs of liver dysfunction underlines the aggravating impact of HIV coinfection on the course of acute HA.

Furthermore, 2 of the $4(50 \%)$ HIV (+) patients were also reported to be MSM. The number of MSM and travel anamnesis to high-endemic countries is likely underreported, as many clinical records we reviewed did not include information about the presence or absence of these risk factors. Despite this fact, the high numbers of travel anamnesis and MSM reported in our study underline the importance of vaccination in these risk populations.

In patients with severe HA hepatitis and liver dysfunction, the maximum of AST and ALT levels peaked simultaneously, while the peak in serum bilirubin was observed 3 days after the ALT maximum. The course of ALT described here is consistent with that described in other recent studies [32]. We observed some HAV infections with prolonged hyperbilirubinemia $(25 / 38,36.2 \%$ with $>5$ days of bilirubin $>5 \mathrm{mg}$ /day). The development of INR elevations over time seems to be influenced by other factors, such as medical interventions, so that interpretation in our cohort in relation to time after maximum liver damage may be difficult.

Symptoms and clinical findings recorded most often in severe HA hepatitis with liver dysfunction were fatigue/ malaise $(81.6 \%)$, nausea/vomiting $(86.8 \%)$, abdominalgia 
$(52.6 \%)$, and hepatomegaly $(39.5 \%)$. While the symptom frequencies for nausea/ vomiting and fatigue in this study are comparable to those previously published, abdominalgia pruritus, dark urine, and fever were reported less often in our cohort, likely due to lower patient age and incomplete documentation of symptoms [25]. Our data, however, are comparable to a smaller Mexican study with a study population of comparable age [30].

We observed 19/44 (43.2\%) cholestatic courses among patients with severe HA hepatitis, with a peak bilirubin $>5 \mathrm{mg} /$ $\mathrm{dL}$ and peak an ALP $>2 \times$ the gender-specific ULN. Only in 2/38 patients with severe HA hepatitis and liver dysfunction, prolonged bilirubinemia $>29$ days was documented. This relatively low number of prolonged bilirubinemia corresponds well with the young patient collective in our study.

In our cohort, there was no statistically significant difference in hospitalization rate between patients with and without signs of liver dysfunction. As this study was conducted in a hospital, close monitoring in the outpatient setting for these patients was possible, while if these patients presented in a practice, they most likely would have been referred to a hospital.

In our study, two patients with severe HA hepatitis died within 30 days. Importantly, these two patients did not develop liver dysfunction and died due to no-liver related causes.

Despite a high percentage $(6.6 \%)$ of HAV-associated liver dysfunction in our cohort, only one patient with fulminant liver failure required liver transplantation. He was infected with HAV while traveling to a high-endemic region (safari in Namibia). While no preexisting liver disease was documented, he suffered from type II diabetes mellitus.

Another patient was evaluated for urgent liver transplantation. She had received her first transplant, for primary biliary cholangitis, several years before infection with HAV. As the planned live-donor liver transplantation could not be performed, because the organ was small for size, she was transferred to another center outside of Austria for further treatment and transplantation and therefore lost to follow-up. Overall, this result in a much lower transplantation rate in patients with severe hepatitis as compared with those reported from other regions. A French study reports transplantation rates up to $50 \%$, although their case definitions vary from the one used in our study [12].

This study describes the epidemiologic trends and disease courses of acute HAV infections in a large cohort in a tertiary center. While the reported incidence of HAV infection in Austria was 0.91 infections/100,000 inhabitants/year in 2018, the disease course and distribution of risk factors particular to Austria have not been previously described [16]. Most studies of HAV severe are conducted on smaller populations.

Limitations of this study include its retrospective design; therefore, data were not documented systematically, and factors of epidemiological interest such as travel history and risk profile might have been underreported. The data were gathered in a tertiary center in Vienna, Austria where severe disease courses and patient groups at risk may be more prevalent as compared with other health care institutions and certainly as compared with the general population.

Austria is a country with a low HAV endemicity; therefore, it is likely that many of the $\operatorname{IgM}(+)$ without severe hepatitis are false positive. Additionally, persons without symptoms and marked laboratory deviations are less likely to present themselves at a hospital. Only 2/41 $(4.9 \%)$ patients with $\operatorname{IgM}(+)$ and AST or ALT $<3 \times$ ULN had confirmed HAV viremia by HAV-RNA PCR. In contrast, $3 / 6(50 \%)$ patients with $\operatorname{IgM}(+)$ and AST or ALT 3-5 $\times$ ULN had confirmed HAV viremia by HAV-RNA by PCR. While limited by the low number of HAV-RNA PCRs performed, these results suggest that in many cases of isolated HAV-IgM (+) seropositivity, the result might be false positive if AST or ALT elevations are not higher $>3 \times$ ULN. However, the HAV-IgM (+) titers and the clinical context have to be considered and, ultimately, in any case of clinical suspicion confirmatory HAV-RNA testing by PCR should be performed, since there are known cases of HAV-RNA viremia in patients with HAV-IgM (+) who have normal levels of AST and ALT. HAV-RNA PCR results were available in 21/38 (55.3\%) patients with a severe course of HAV hepatitis and liver dysfunction. The fact that all 21 of these PCRs showed HAV-RNA viremia indicates a high probability that HAV-RNA viremia was prevalent in most of the 38 patients in this subgroup. Quantitative HAV-IgM increased from HAV-IgM (+) with low transaminases, to $\operatorname{IgM}(+)$ with AST or ALT 3-5 $\times$ ULN, to severe HA hepatitis without liver dysfunction and was highest in severe HA hepatitis with liver dysfunction. The median quantitative HAV-IgM values for the first 3 groups were in the range usually associated with possible HAV infection, while the median value in the severe HA hepatitis with liver dysfunction was in the range clearly indicating recent $\mathrm{HAV}$ vaccination or $\mathrm{HAV}$ infection. Structured performance of HAV-RNA PCR testing, including reflexive PCR in case of a positive anti-HAV$\operatorname{IgM}(+)$ serology result, could improve the diagnostic rate of viremic $\mathrm{HAV}$ infection.

Our study indicates a recent increase in HAV infections with a severe course-which seems to be more prevalent in certain risk groups. Thus, prevention by vaccination, travel hygiene, and food safety is of foremost importance. Effective strategies aiming at increasing vaccination rates against $\mathrm{HAV}$ in risk groups such as travelers to high-endemic countries, and individuals living with HIV and MSM, in particular those engaging in multinational networks, should be developed and employed. 
Acknowledgments We thank the Center for Virology of the Medical University of Vienna and Prof. Stephan Aberle in particular for valuable intellectual support and input, providing results of past HAV-RNA PCRs and for performing HAV-RNA PCRs and HIV testing on stored sera of suspected HAV cases.

Authors' contributions Study design: David BAUER, Thomas REIBERGER. Data acquisition: David BAUER, David CHROMY, Anna FARTHOFER, Michael TRAUNER, Ralf SCHMIDT, Robert STRASSL, Florian MAYER, Heidemarie HOLZMANN, Thomas REIBERGER. Statistical analysis: David BAUER. Critical revision of intellectual content and approval of final manuscript: David BAUER, Anna FARTHOFER, David CHROMY, Benedikt SIMBRUNNER, Lisa STEININGER, Caroline SCHMIDBAUER, Theresa BINTER, Michael TRAUNER, Mattias MANDORFER, Ralf SCHMIDT, Robert STRASSL, Florian MAYER, Heidemarie HOLZMANN, Thomas REIBERGER.

Funding Open access funding provided by Medical University of Vienna.

\section{Compliance with ethical standards}

Conflict of interest D.B. received travel support from AbbVie and Gilead.

F.A. none declared.

C.D. served as a speaker and/or consultant and/or advisory board member for AbbVie, Gilead, and MSD, and received travel support from AbbVie, MSD, ViiV Healthcare, and Gilead.

S.B. received travel support by AbbVie and Gilead.

S.L. none declared.

S.C. received travel support from AbbVie, Gilead, and Gebro.

M.M. served as a speaker and/or consultant and/or advisory board member for AbbVie, Bristol-Myers Squibb, Collective Acumen, Gilead, and W. L. Gore \& Associates and received travel support from AbbVie, Bristol-Myers Squibb, and Gilead.

S.R. none decleared.

T.M. received speaker fees from BMS, Falk, Gilead, Intercept and MSD; advisory board fees from Albireo, BiomX, Boehringer Ingelheim, Falk, Genfit, Gilead, Intercept, MSD, Novartis, Phenex, Regulus, and Shire. He further received travel grants from Abbvie, Falk, Gilead, Intercept and Jansen and unrestricted research grants from Albireo, Cymabay, Falk, Gilead, Intercept, MSD, and Takeda.

ST.R. none declared.

M.F. none declared.

H.H. none declared.

T.R. received grant support from Abbvie, Boehringer Ingelheim, Gilead, MSD, Philips Healthcare, and Gore; speaking honoraria from Abbvie, Gilead, Gore, Intercept, Roche, and MSD; consulting/advisory board fee from Abbvie, Bayer, Boehringer Ingelheim, Gilead, Intercept, MSD, and Siemens; and travel support from Boehringer Ingelheim, Gilead, and Roche.

Ethics approval This study was approved by the ethics committee of the Medical University of Vienna (No. 1968/2018) and conducted in accordance with the Helsinki declaration, as revised 2013 and the guidelines for good scientific practice of the Medical University of Vienna.

Abbreviations ALP, alkaline phosphatase; ALT, alanine transaminase; AST, aspartate aminotransferase; BL, baseline; EEC, European Economic Area; EU, European Union; gGT, gamma-glutamyl transferase; GT, Genotype; HA, hepatitis A; HAV, hepatitis A virus; Hb, hemoglobin; HE, hepatic encephalopathy; HEV, hepatitis E virus; HIV, human immunodeficiency virus; IgG, immunoglobulin G; IgM, immunoglobulin
M; INR, international normalized ratio; IQR, interquartile range; MSM, men who have sex with men; Na, sodium; NH3, ammonia; |, or (inclusive or); PLT, platelets; ULN, upper limit of normal; WBC, white blood cell count; (+), postive; (-), negative

Open Access This article is licensed under a Creative Commons Attribution 4.0 International License, which permits use, sharing, adaptation, distribution and reproduction in any medium or format, as long as you give appropriate credit to the original author(s) and the source, provide a link to the Creative Commons licence, and indicate if changes were made. The images or other third party material in this article are included in the article's Creative Commons licence, unless indicated otherwise in a credit line to the material. If material is not included in the article's Creative Commons licence and your intended use is not permitted by statutory regulation or exceeds the permitted use, you will need to obtain permission directly from the copyright holder. To view a copy of this licence, visit http://creativecommons.org/licenses/by/4.0/.

\section{References}

1. Hollinger FB TJ (1996) Hepatitis A virus. In: Fields Virology. Philadelphia: Lippincott-Raven. p 735-82.10.1007

2. Bianco E, Stroffolini T, Spada E, Szklo A, Marzolini F, Ragni P et al (2003) Case fatality rate of acute viral hepatitis in Italy: 19952000. An update. Dig Liver Dis [Internet] [cited 2020 10];35:404 8. https://linkinghub.elsevier.com/retrieve/pii/ S1590865803001579 https://doi.org/10.1016/S1590-8658(03) 00157-9

3. Wang H, Naghavi M, Allen C, Barber RM, Carter A, Casey DC et al (2016) Global, regional, and national life expectancy, all-cause mortality, and cause-specific mortality for 249 causes of death, 1980-2015: a systematic analysis for the Global Burden of Disease Study 2015. Lancet 388:1459-1544. https://doi.org/10. 1016/S0140-6736(16)31012-1

4. Lednar WM, Lemon SM, Kirkpatrick JW, Redfield RR, Fields ML, Kelley PW (1985) Frequency of illness associated with epidemic hepatitis a virus infections in adults. Am J Epidemiol [Internet] [cited 2020 8];122:226-33. http://www.ncbi.nlm.nih.gov/pubmed/ 3860002 https://doi.org/10.1093/oxfordjournals.aje.a114093

5. Pischke, Sven WH (2020) Hepatitis A [Internet]. In: Mauss, Stefan Berg, Thomas, Rockstroh, Jürgen Sarrazin, Christoph, Wedemeyer H (eds) Hepatology - a clinical textbook. [cited 2020 10]. p 36-7. https://www.hepatologytextbook.com/

6. Chromy D, Mandorfer M, Bucsics T, Schwabl P, Scheiner B, Schmidbauer C et al (2019) High efficacy of interferon-free therapy for acute hepatitis C in HIV-positive patients. United Eur Gastroenterol J [Internet] [cited 2020 10];7:507-16. http://www. ncbi.nlm.nih.gov/pubmed/31065368. https://doi.org/10.1177/ 2050640619835394

7. Koff RS, Hepatitis A (1998) Lancet 30(351):1643-1649. https:// doi.org/10.1016/S0140-6736(98)01304-X

8. Kroneman A, de Sousa R, Verhoef L, Koopmans MPG, Vennema H (2018) Usability of the international HAVNet hepatitis A virus database for geographical annotation, backtracing and outbreak detection. Eurosurveillance. https://doi.org/10.2807/1560-7917.ES. 2018.23.37.1700802

9. Vaughan G, Goncalves Rossi LM, Forbi JC, de Paula VS, Purdy MA, Xia G et al (2014) Hepatitis A virus: host interactions, molecular epidemiology and evolution. Infect Genet Evol 21:227-243. https://doi.org/10.1016/j.meegid.2013.10.023

10. Brown GR, Persley K (2002) Hepatitis A epidemic in the elderly. South Med J. https://doi.org/10.1097/00007611-200295080-00010 
11. Chen N-Y, Liu Z-H, Shie S-S, Chen T-H Wu T-S(2017) Clinical characteristics of acute hepatitis A outbreak in Taiwan, 2015-2016: observations from a tertiary medical center. BMC Infect Dis [Internet] [cited 2020 21];17:441. http://bmcinfectdis. biomedcentral.com/articles/10.1186/s12879-017-2555-x https:// doi.org/10.1186/s12879-017-2555-x

12. Rezende G, Roque-Afonso AM, Samuel D, Gigou M, Nicand E, Ferre V et al (2003) Viral and clinical factors associated with the fulminant course of hepatitis A infection. Hepatology. https://doi. org/10.1053/jhep.2003.50366

13. (2012) WHO position paper on hepatitis A vaccines - June 2012. Wkly Epidemiol Rec 87:261-76

14. Adult Immunization Schedule by Vaccine and Age Group | CDC [Internet]. [cited 2020 8]; https://www.cdc.gov/vaccines/schedules/ hcp/imz/adult.html\#note-hepa

15. Beneka B, Fischer K, Holzmann H, Jean-Paul K, WiedermannSchmidt U Zwiauer K (2020) Impfplan Österreich 2020 [Internet]. https://www.sozialministerium.at/dam/jcr:a0cf83df7c20-48ac-b024-e6015a45a753/200103_Impfplan_Österreich 2020 pdfUA.pdf

16. Übertragbare Krankheiten [Internet]. [cited 2020 8]; http://www. statistik.at/web_de/statistiken/menschen_und_gesellschaft/ gesundheit/gesundheitszustand/uebertragbare_krankheiten/ 022361.html

17. ECDC (2016) Hepatitis A virus in the EU/EEA, 1975-2014 [Internet]. [cited 2020 8]. https://www.ecdc.europa.eu/en/ publications-data/hepatitis-virus-eueea-1975-2014 https://doi.org/ $10.2900 / 60930$

18. Carrillo-Santisteve P, Tavoschi L, Severi E, Bonfigli S, Edelstein M, Byström E et al (2017) Seroprevalence and susceptibility to hepatitis A in the European Union and European Economic Area: a systematic review. Lancet Infect Dis 17:e306-e319. https://doi. org/10.1016/S1473-3099(17)30392-4

19. Enkirch T, Eriksson R, Persson S, Schmid D, Aberle SW, Löf E et al (2018) Hepatitis a outbreak linked to imported frozen strawberries by sequencing, Sweden and Austria, June to September 2018. Eurosurveillance. https://doi.org/10.2807/1560-7917.ES. 2018.23.41.1800528

20. Patricia N, Freidl Gudrun S, Williams Christopher J, Otilia M, Carmen V, Ana A, Ingrid F, Harry V, Kazim B, Lin NS, Michael E, Alison S-P, Niamh M, Jonathan D, Mirko F, Wenzel J M of the EHAOIT (2018) Hepatitis A outbreak disproportionately affecting men who have sex with men (MSM) in the European Union and European Economic Area, June 2016 to May 2017. Euro Surveill 23. https://doi.org/10.2807/1560-7917.ES.2018.23.33.1700641

21. R Core Team (2019) R: A Language and Environment for Statistical Computing [Internet]. https://www.r-project.org/

22. Hadley Wickham, Romain François LH and KM (2018) dplyr: A Grammar of Data Manipulation [Internet]. https://cran.r-project. org/package $=$ dplyr
23. Walker A (2019) openxlsx: Read, Write and Edit XLSX Files [Internet]. https://cran.r-project.org/package=openxlsx

24. Yoshida K (2019) tableone: Create "Table 1" to Describe Baseline Characteristics [Internet]. https://cran.r-project.org/package= tableone

25. Gust ID, Feinstone SM (1988) Hepatitis A, 1st edn. CRC Press Inc. https://doi.org/10.1201/9781351073172

26. Freidl GS, Sonder GJ, Bovée LP, Friesema IH, van Rijckevorsel GG, Ruijs WL et al (2017) Hepatitis a outbreak among men who have sex with men (MSM) predominantly linked with the EuroPride, the Netherlands, July 2016 to February 2017. Eurosurveillance. https://doi.org/10.2807/1560-7917.ES.2017.22. 8.30468

27. Rivas V, Barrera A, Pino K, Núñez R, Caceres CJ, Lopez-Lastra M et al (2018) Hepatitis a outbreak since november 2016 affecting men who have sex with men (MSM) in Chile connected to the current outbreak in MSM in Europe, situation up to October 2017. Eurosurveillance [Internet] [cited 2020 21];23. https:// pubmed.ncbi.nlm.nih.gov/29510780/ https://doi.org/10.2807/ 1560-7917.ES.2018.23.9.18-00060

28. Gozlan Y, Bar-Or I, Rakovsky A, Savion M, Amitai Z, Sheffer R et al (2017) Ongoing hepatitis A among men who have sex with men (MSM) linked to outbreaks in Europe in Tel Aviv area, Israel, December 2016-June 2017. Euro Surveill Bull Eur sur les Mal Transm = Eur Commun Dis Bull 22. https://doi.org/10.2807/ 1560-7917.ES.2017.22.29.30575

29. Ajmera V, Xia G, Vaughan G, Forbi JC, Ganova-Raeva LM, Khudyakov Y et al (2011) What factors determine the severity of hepatitis A-related acute liver failure? J Viral Hepat. https://doi.org/ 10.1111/j.1365-2893.2010.01410.x

30. Mackinney-Novelo I, Barahona-Garrido J, Castillo-Albarran F, Santiago-Hernández JJ, Méndez-Sánchez N, Uribe M et al (2012) Clinical course and management of acute hepatitis a infection in adults. Ann Hepatol 11:652-657. https://doi.org/10.1016/s16652681(19)31438-3

31. Beyrer C, Baral SD, Van Griensven F, Goodreau SM, Chariyalertsak S, Wirtz AL et al (2012) Global epidemiology of HIV infection in men who have sex with men. Lancet 380:367377. https://doi.org/10.1016/S0140-6736(12)60821-6

32. Lanford RE, Feng Z, Chavez D, Guerra B, Brasky KM, Zhou Y et al (2011) Acute hepatitis A virus infection is associated with a limited type I interferon response and persistence of intrahepatic viral RNA. Proc Natl Acad Sci U S A 108:11223-11228. https:// doi.org/10.1073/pnas.1101939108

Publisher's note Springer Nature remains neutral with regard to jurisdictional claims in published maps and institutional affiliations. 